\title{
ANALISIS KEKUATAN DIELEKTRIK MINYAK CAMPURAN METIL ESTER BUNGA MATAHARI SEBAGAI ISOLASI CAIR PADA TRANSFORMATOR
}

\author{
Ferry R A Bukit ${ }^{1}$
}

Departemen Teknik Elektro, Universitas Sumatera Utara, Medan, Indonesia ${ }^{1}$

email: ferrybukit@usu.ac.id

\begin{abstract}
High-voltage equipment plays a vital role in the electric power system. To keep it in optimal operating condition, a good equipment isolation system is required. Liquid insulation is widely used compared to gas insulation, especially in power transformers. It is due to having a high-density level, where the value is 1000 times that of gas insulation. Vegetable oil can be an alternative as a substitute or mixture of petroleum because vegetable oil is a renewable natural resource. Its availability is guaranteed and environmentally friendly. In this study, an analysis of the dielectric strength characteristics of sunflower methyl ester oil with a mixture of five samples of mineral oil was carried out as an alternative material for liquid insulation in transformers. The breakdown voltage measurement method is based on standardization that refers to IEC 60156-95. The measurement uses a ball type electrode with an electrode distance of $2.5 \mathrm{~mm}$ at four temperature conditions. Based on the SPLN 49-1-1982 standard, sunflower seed methyl ester oil meets the new insulating oil breakdown voltage standard, $30 \mathrm{kV} / 2.5 \mathrm{~mm}$ or the same as a dielectric strength of $120 \mathrm{kV} / \mathrm{cm}$ where sample D is a mixture of $30 \%$ sunflower seed methyl ester oil with $70 \%$ mineral oil which has the highest dielectric strength of $290.74 \mathrm{kV} / \mathrm{cm}$ at a test temperature of $80^{\circ} \mathrm{C}$. .
\end{abstract}

Keywords: Sunflower, Insulating Liquid, Methyl Esters, Transformer.

\begin{abstract}
Abstrak
Peralatan tegangan tinggi memegang peranan terpenting dalam sistem tenaga listrik. Untuk menjaga peralatan dalam kondisi operasi yang optimal diperlukan sistem isolasi peralatan yang baik. Isolasi cair banyak digunakan dibandingkan isolasi gas khususnya pada transformator daya. Hal ini disebabkan memiliki tingkat massa jenis yang tinggi, dimana nilainya 1000 kali daripada isolasi gas. Penggunaan minyak nabati dapat menjadi alternatif sebagai pengganti atau campuran minyak bumi karena minyak nabati merupakan sumber daya alam yang terbaharukan sehingga ketersediaannya terjamin serta ramah lingkungan. Pada penelitian ini dilakukan analisis karakteristik kekuatan dielektrik minyak metil ester bunga matahari dengan campuran minyak mineral sebanyak lima sampel sebagai bahan alternatif isolasi cair pada transformator. Metode pengukuran tegangan tembus berdasarkan standarisasi yang mengacu kepada IEC 60156-95, dimana pengukuran menggunakan elektroda jenis bola-bola dengan jarak elektroda $2.5 \mathrm{~mm}$ pada empat kondisi temperatur. Berdasarkan standar SPLN 49-1-1982 minyak metil ester biji bunga matahari memenuhi standar tegangan tembus minyak isolasi baru yaitu $\geq 30 \mathrm{kV} / 2.5 \mathrm{~mm}$ atau sama dengan kekuatan dielektrik sebesar $\geq 120 \mathrm{kV} / \mathrm{cm}$. Dimana sampel D merupakan campuran antara $30 \%$ minyak metil ester biji bunga matahari dengan $70 \%$ minyak mineral yang memiliki kekuatan dielektrik tertinggi sebesar $290.74 \mathrm{kV} / \mathrm{cm}$ pada suhu uji $80^{\circ} \mathrm{C}$.
\end{abstract}

Kata Kunci: Bunga Matahari, Isolasi Cair, Metil Ester, Transformator

\section{PENDAhULUAN}

Pada umumnya, kebanyakan transformator menggunakan isolasi cair yang terbuat dari olahan minyak bumi, seperti Shell Diala, Gulf, Nynas dan lain-lain. Penggunaan minyak bumi secara terus menerus menimbulkan masalah utama yaitu minyak bumi memiliki persediaan yang terbatas dalam perut bumi. Berdasarkan data statistik yang dikeluarkan oleh Badan Pusat Statistik, produksi minyak bumi (crude oil) di Indonesia mengalami penurunan sebanyak 287.902 juta barel pada tahun 2014 menjadi 273.494 juta barel pada tahun 2019 [1]. Hal ini disebabkan oleh beberapa faktor seperti usia umur minyak yang tua, kerusakan peralatan, gangguan alam, dan lain-lain. Oleh karena itu, dibutuhkan sebuah alternatif bahan isolasi cair yang berasal dari bahan minyak nabati. Penggunaan minyak nabati dapat menjadi jawaban atas permasalahan yang ditimbulkan oleh minyak bumi karena minyak nabati merupakan sumber daya alam yang terbaharukan sehingga ketersediaannya terjamin serta ramah lingkungan [2]. Disisi lain, minyak nabati memiliki keunggulan diantaranya tidak beracun, memiliki nilai titik nyala (flash point) dan fire point yang tinggi, dan memiliki karakteristik termal yang baik [3].

Penelitian sebelumnya yang berjudul "Experimental Analysis on the Combination of Jatropha Oil and Silk Cotton
Oil for Transformer" [4] melakukan experimen dan analisis dari penggunaan minyak nabati yakni mencampurkan minyak jarak dan minyak biji kapas sebagai isolasi cair pada trafo dengan variasi komposisi dengan standar pengujian IS 3351993. Nilai tegangan tembus untuk komposisi $20 \%$ minyak jarak dan $80 \%$ minyak biji kapas mendapatkan hasil pengujian sebesar $26 \mathrm{kV}$ sedangkan untuk komposisi $80 \%$ minyak jarak dan $20 \%$ minyak biji kapas mendapatkan hasil pengujian sebesar $48 \mathrm{kV}$. Hasil pengujian ini menjadi sebuah potensi penggunaan minyak jarak dan minyak biji kapas untuk dijadikan isolasi cair pada trafo.

Inmaculada Fernández dan rekan melakukan penelitian berjudul "Comparative evaluation of alternative fluids for power transformers" [5], yaitu evaluasi yang membandingkan beberapa jenis minyak isolasi salah satunya minyak nabati dalam hal ini adalah bunga matahari, minyak kanola, kelapa sawit minyak, minyak rapeseed, minyak kedelai dan minyak zaitun. Penulis menyampaikan perbandingan kualitatif minyak nabati untuk sifat fisik, kimia dan dielektrik minyak serta perilaku isolasi cair tersebut saat sudah menua. Hasil yang didapat, penulis menyarankan minyak bunga matahari $(45 \mathrm{kV})$, rapeseed $(73 \mathrm{kV})$, kanola $(45 \mathrm{kV})$ dan minyak kedelai $(51 \mathrm{kV})$ sangat baik digunakan sebagai minyak isolasi. 
Penelitian selanjutnya yang berjudul "Minyak Kepala Beraditif Minyak Zaitun sebagai Isolasi Perlatan Tegangan Tinggi" [6] melakukan peningkatan level kekuatan dielektrik minyak kepala dengan menggunakan minyak zaitun agar dapat digunakan sebagai alternatif isolasi cair pada peralatan tegangan tinggi. Peningkatan level tegangan tembus dilakukan dengan menambahkan kadar minyak zaitun sebesar 5\%-25\% ke dalam minyak kelapa. Hasil dari penambahan kadar minyak zaitun didapatkan nilai tegangan tembus optimum yaitu $38,73 \mathrm{kV} / 2,5 \mathrm{~mm}$ dan jika dilakukan pemanasan guna mengurangi kadar air yang terkandung dalam minyak dapat mencapai $51,15 \mathrm{kV} / 2,5 \mathrm{~mm}$.

Eksperimen lain dipaparkan oleh sebuah artikel jurnal dengan judul "Dielectric Properties of Natural Ester Oils Used for Transformer Application Under Temperature Variation" [7] melakukan studi perbandingan sifat elektrik pada sebuah minyak isolasi meliputi konstanta dielektrik, faktor disipasi $(\tan \delta)$, dan resistivitas dari lima jenis minyak berbeda yaitu minyak bekatul, minyak kelapa, minyak jagung, minyak biji bunga matahari, minyak kanola. Hasil eksperimen menyimpulkan bahwa minyak kanola sangat cocok untuk dijadikan minyak isolasi pada transformator. Hal ini berdasarkan hasil yang didapat nilai kontanta dielektrik minyak kanola yang tinggi, faktor disipasi (tan $\delta$ ) yang rendah, dan resistivitasnya tinggi.

Penelitian yang dilakukan oleh R. A. Sitompul dan Syahrawardi dengan judul "Analisis Kekuatan Dielektrik Minyak Kedelai (Soybean Oil) Dengan Variasi Suhu Sebagai Alternatif Minyak Isolasi" [8] mendapatkan hasil kekuatan dielektrik minyak kedelai paling tinggi diperoleh 116,14 $\mathrm{kV} / \mathrm{cm}$ dan menyimpulkan bahwa apabila suhu minyak kedelai semakin tinggi maka kekuatan dielektrik minyak tersebut akan menurun. Apabila umur minyak semakin lama, kekuatan dielektrik akan menurun hal ini dipengaruhi oleh kontaminasi dan oksidasi pada minyak, sehingga dihasilkan zat-zat yang cenderung menurunkan kekuatan dielektrik minyak itu sendiri.

Penelitian lainnya dengan judul "Investigation on Partial Discharge, Dielectric and Thermal Characteristic of Nano SiO2 Modified Sunflower Oil for Power Transformer Applications" [9] melakukan pengujian partial discharge, impuls petir, tegangan tembus, tan-delta, konstanta dielektrik, resistivitas volume, kapasitansi, viskositas, titik nyala dan titik api terhadap minyak bunga matahari murni dan minyak bunga matahari yang dimodifikasi dengan patrikel nano $\mathrm{SiO} 2$. Dari hasil percobaan, penulis menyimpulkan bahwa sampel minyak bunga matahari yang dimodifikasi dengan partikel nano memiliki sifat isolasi yang lebih baik daripada sampel minyak murni. Sampel minyak bunga matahari yang dimodifikasi ini memiliki karakteristik dielektrik yang lebih baik dibandingkan dengan minyak mineral.

Berdasarkan pertimbangan di atas maka peneliti melakukan pengolahan terhadap minyak kedelai melalui proses reaksi kimiawi transesterfikasi agar diperoleh minyak metil ester kedelai (Soybean Methyl Ester Oil). Material minyak kedelai yang akan diolah didapat dari minyak yang beredar dipasaran. Penelitian ini melakukan pengujian terhadap minyak metil ester kedelai meliputi pengujian tegangan tembus (breakdown voltage), dan menguji sifat kimia-fisik material tersebut (tingkat kekentalan, bilangan asam, dan titik nyala). Kemudian, dilakukan perbandingan kekuatan dielektrik antara sampel uji minyak metil ester kedelai murni dengan minyak metil ester kedelai yang dicampur dengan minyak mineral dengan perbandingan komposisi $10 \%$ minyak metil ester kedelai - 90\% minyak mineral, $20 \%$ minyak metil ester kedelai - 80\% minyak mineral, dan 30\% minyak metil ester kedelai - 70\% minyak mineral. Penelitian ini diharapkan dapat mengetahui kelayakan minyak metil ester kedelai tersebut dan juga dengan campurannya sebagai alternatif isolasi cair pada transformator.

\section{KAJIAN PUSTAKA}

\section{A. Kekuatan Dielektrik}

Kekuatan dielektrik merupakan ukuran kemampuan suatu material untuk bisa menahan medan elektrik tanpa berakibat terjadinya tembus listrik pada material isolasi tersebut. Kekuatan dielektrik cair tergantung pada sifat atom dan molekul cairan itu sendiri. Namun pada dasarnya kekuatan dielektrik dipengaruhi oleh beberapa hal yaitu material dari elektroda, suhu, jenis tegangan yang diberikan, gas yang terdapat dalam cairan, dan sebagainya yang dapat merubah sifat molekul cairan. Dalam isolasi cair kekuatan dielektrik setara dengan tegangan yang terjadi.

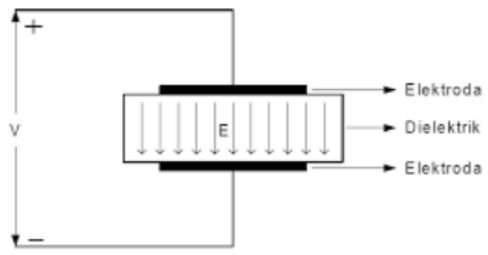

Gbr 1. Rangkaian Dielektrik diantara Dua Buah Elektroda

Apabila suatu dielektrik ditempatkan diantara dua elektroda piring sejajar seperti ditunjukkan oleh Gambar 1. kemudian elektroda tersebut diberi tegangan, maka di dalam dielektrik tersebut akan timbul medan listrik. Medan listrik ini akan memberi gaya kepada elektron-elektron agar terlepas dari ikatannya dan menjadi elektron bebas. Peristiwa ini akan menyebabkan dielektrik berubah sifat menjadi konduktor akibat mendapat beban medan listrik. Setiap dielektrik memiliki batas kekuatan untuk memikul terpaan listrik. Jika beban medan listrik yang dipikul suatu bahan isolasi melebihi batas tersebut, maka dielektrik akan menghantar arus atau gagal melaksanakan fungsinya sebagai isolator yang pada akhirnya dapat membuat bahan isolasi mengalami tembus listrik. Tegangan tembus atau "breakdown voltage" dapat diartikan sebagai nilai tegangan yang menimbulkan kuat medan listrik pada suatu bahan isolasi sama dengan atau lebih besar dari kekuatan dielektrik bahan isolasi tersebut. Proses sampai terjadinya tembus listrik memerlukan waktu beberapa mikrodetik dan lamanya tidak tentu tetapi bersifat statistik. Peristiwa medan listrik ini tidak selalu mengakitbatkan bahan isolasi mengalami tembus listrik, tetapi ada 2 syarat yang harus dipenuhi agar bahan isolasi mengalami tembus listrik yaitu [10]:

1. Besar kapasitas medan elektrik bahan isolasi harus lebih besar atau sama dengan kekuatan dielektrik bahan isolasi;

2. Lama medan listrik yang terjadi lebih besar atau sama dengan waktu tunda tembus listrik. 
Kuat medan listrik yang dapat ditahan oleh bahan dielektrik dapat didefisinikan sebagai perbandingan antara tegangan yang menyebabkan tembus listrik $(\mathrm{kV})$ dengan tebal isolasi (d) yang membentuk jarak antara kedua elektroda. Hal ini dapat dilihat pada Persamaan 1 :

$$
\mathrm{E}=\mathrm{V} / \mathrm{d}
$$

dimana :

$\mathrm{E}=$ Kuat medan listrik yang dapat ditahan oleh bahan dielektrik $(\mathrm{kV} / \mathrm{cm})$

$\mathrm{V}=$ Tegangan maksimum yang dibaca oleh alat ukur $(\mathrm{kV})$

$\mathrm{d}=$ Tebal isolasi $(\mathrm{cm})$

B. Isolasi Cair

Bahan isolasi cair harus memiliki karakteristik tegangan tembus yang tinggi. Selain itu isolasi cair berfungsi sebagai media pendingin ketika terjadi kenaikan temperatur (suhu) pada transformator. Apabila isolasi cair tidak dapat menjadi media pendingin transformator, maka dapat merusak isolasi kertas pada gulungan (coil) di dalam transformator, di sisi lain suhu yang terlalu panas juga dapat menurunkan kualitas tahanan isolasi yang dapat mengakibatkan mengalirnya arus antara phasa dengan phasa dan phasa dengan body di dalam transformator sehingga dapat menimbulkan kerusakan pada transformator. Bahan isolasi cair juga harus sebagai isolator yang baik. Hal ini merupakan sesuatu yang mutlak untuk menghindari terjadinya short circuit atau hubung singkat di dalam transformator baik antara phasa maupun sisi phasa dengan body, dimana hubung singkat tersebut akan mengakibatkan transformator meledak.

\section{Karakteristik Isolasi Cair}

Dielektrik minyak sebagai salah satu material listrik memiliki beberapa karakteristik kelistrikan. Karakteristik tersebut diantaranya sifat listrik pada sebuah material dielektrik cair, karakterisik perpindahan panas.

\section{Sifat Listrik}

\subsection{Withstand Breakdown}

Withstand Breakdown merupakan kemampuan suatu bahan isolasi untuk tidak mengalami ketembusan dalam kondisi tekanan listrik (electric stress) yang tinggi.

\subsection{Permitivitas Relatif}

Permitivitas relatif atau konstanta dielektrik adalah rasio energi listrik yang tersimpan pada bahan dielektrik yang berada diantara dua pelat logam terhadap relatif udara atau ruang hampa. Permitivitas relatif akan menentukan nilai kapasitansi listrik suatu bahan isolasi. Nilai kapasitansi ini berhubungan dengan intensitas medan listrik (E) dan kerapatan fluks (D) serta permitivitas ruang hampa ( $\varepsilon 0)$ dan permitivitas bahan (cr). Berdasarkan hukum Gauss besarnya kerapatan fluks listrik yang menembus setiap permukaan tertutup sama dengan muatan total yang dilingkupi oleh permukaan tersebut. Hal ini ditunjukan oleh Persamaan 2. berikut:

$$
\mathrm{D}=\mathrm{Q} / \mathrm{A}
$$

dimana:

$$
\begin{aligned}
& \mathrm{D}=\text { kerapatan fluks listrik }(\mathrm{C} / \mathrm{m} 2) \\
& \mathrm{Q}=\text { besar muatan (Coloumb) } \\
& \mathrm{A}=\text { Luas penampang }(\mathrm{m} 2)
\end{aligned}
$$

Dimana diketahui bahwa intensitas medan listrik mendapat pengaruh dari permitivitas bahan dan rapat fluks. Sehingga besarnya E dapat dihitung dengan Persamaan 3. berikut :

$$
\mathrm{E}=\mathrm{D} /(\varepsilon 0 \cdot \varepsilon \mathrm{r})
$$

dimana:

$\varepsilon 0=$ permitivitas ruang hampa $(8.85 \times 10-12 \mathrm{C} 2 / \mathrm{Nm} 2)$

$\varepsilon r=$ permitivitas relatif bahan

Kapasitansi yang dihasilkan dari kedua plat sejajar adalah sebagai berikut:

$$
\mathrm{C}=\mathrm{Q} / \mathrm{V}
$$

$\mathrm{V}=$ Tegangan antara kedua plat sejajar

Selanjutnya diketahui bahwa:

$$
\mathrm{V}=(\mathrm{Q} \cdot \mathrm{d}) /(\varepsilon 0 \cdot \varepsilon \mathrm{r} \cdot \mathrm{A})
$$

Kemudian substitusi Persamaan 5. ke Persamaan 4., sehingga didapatkan Persamaan 6 berikut:

\subsection{Faktor Disipasi}

$$
\mathrm{C}=(\varepsilon 0 \cdot \varepsilon r \cdot \mathrm{A}) / \mathrm{d}
$$

Faktor disipasi atau tan delta $(\tan \delta)$ adalah faktor rugirugi daya minyak transformator. Kinerja daripada sebuah bahan isolasi cair dipengaruhi oleh faktor disipasi tegangan tinggi bolak-balik, ketika isolasi dalam kondisi berbeban akan menimbulkan sejumlah rugi-rugi dielektrik. Faktor disipasi sebagai ukuran rugi-rugi daya merupakan parameter yang penting bagi peralatan tegangan tinggi seperti kabel. Minyak transformator murni sendiri mempunyai nilai faktor disipasi yang bervariasi antara 10-4 pada suhu 20 oC dan 103 pada 90 oC pada frekuensi $50 \mathrm{~Hz}$ [11].

\subsection{Resistivitas}

Resistivitas merupakan kemampuan suatu material untuk menghambat arus listrik. Resistivitas dinyatakan dalam satuan $\Omega$-m. Suatu cairan dapat digolongkan sebagai isolasi cair bila resistivitasnya lebih besar dari $109 \Omega-\mathrm{m}$. Pada sistem tegangan tinggi, resistivitas yang diperlukan untuk material isolasi adalah $1016 \Omega-\mathrm{m}$ atau lebih.

Jumlah level heading maksimum yaitu tiga tingkat. Penulisan heading pada setiap level menggunakan ukuran format hanging $0.7 \mathrm{~cm}$ dan ditulis rata kiri dan kanan.

\section{Syarat Minyak Isolasi}

Berdasarkan standarisasi yang diterbitkan oleh PLN yaitu SPLN yang mengacu pada IEC, minyak isolasi memiliki syarat-syarat sebagai berikut [12]:

1) Kejernihan (Appearance)

Kejernihan minyak isolasi baru ditunjukkan dengan indikasi skala warna Gardner dengan batas nilai 3.5 dan tidak boleh mengandung suspensi atau endapan (sedimen).

2) Massa jenis (Density)

Massa jenis adalah pengukuran massa setiap satuan volume benda. Massa jenis dibatasi agar air dapat terpisah dari minyak isolasi dan tidak melayang. Standar nilai massa jenis minyak isolasi baru yaitu tidak lebih dari $0,895 \mathrm{~g} / \mathrm{cm}^{3}$.

3) Viskositas (Viscosity)

Viskositas adalah suatu ukuran dari besarnya perlawanan yang diberikan oleh minyak untuk mengalir, atau ukuran dari besarnya tekanan geser bagian dalam dari suatu bahan cair. Viskositas memiliki satuan $\mathrm{mm}^{2} / \mathrm{s}$ atau cSt (centistokes). Viskositas memegang peranan dalam pendinginan, digunakan untuk menentukan kelas minyak dan kurang dipengaruhi oleh kontaminasi atau kerusakan minyak.

4) Titik nyala (Flash Point)

Titik nyala adalah suhu terendah dimana uap minyak mulai menyala. Titik nyala yang rendah menunjukkan 
adanya kontaminasi zat yang mudah terbakar. Batas nilai titik nyala minyak isolasi baru adalah minimal 140 ${ }^{0} \mathrm{C}$ untuk Kelas 1 dan $130{ }^{\circ} \mathrm{C}$ untuk Kelas 2.

5) Titik tuang (Pour Point)

Titik tuang adalah suhu terendah dimana minyak dapat mengalir pada saat didinginkan. Minyak isolasi dengan titik tuang yang rendah akan berhenti mengalir pada temperatur yang rendah. Titik tuang digunakan untuk mengidentifikasi dan menentukan jenis peralatan yang akan menggunakan minyak isolasi. Batas maksimal nilai titik tuang minyak isolasi baru untuk Kelas 1 adalah $-30{ }^{\circ} \mathrm{C}$ dan Kelas 2 adalah $-40{ }^{\circ} \mathrm{C}$.

6) Angka kenetralan (Neutralization number)

Angka kenetralan merupakan harga yang menunjukkan penyusun asam minyak isolasi dan dapat mendeteksi kontaminasi minyak, menunjukkan kecenderungan perubahan kimia atau cacat atau indikasi perubahan kimia dalam bahan tambahan (additive). Angka kenetralan dapat dipakai sebagai petunjuk umum untuk menentukan apakah minyak sudah harus diganti atau diolah. Batas standar angka kenetralan pada minyak isolasi cair baru adalah $0.03 \mathrm{mgKOH} / \mathrm{g}$.

7) Korosi belerang (Corosive Sulphur)

Pengujian korosi belerang ini bertujuan untuk menunjukan adanya kemungkinan korosi yang dihasilkan dari adanya belerang yang tidak stabil dalam minyak isolasi.

8) Tegangan tembus (Breakdown Voltage)

Tegangan tembus adalah nilai tegangan (dalam $\mathrm{kV}$ ) yang menimbulkan kuat medan listrik pada suatu bahan isolasi sama dengan atau lebih besar dari kekuatan dielektrik bahan isolasi tersebut. Tegangan tembus yang terlalu rendah menunjukan adanya kontaminasi berupa air, kotoran, atau partikel konduktif dalam minyak. Batas minimal minyak isolasi sebelum diolah adalah 30 $\mathrm{kV} / 2.5 \mathrm{~mm}$, dan minyak isolasi setelah diolah adalah 50 $\mathrm{kV} / 2.5 \mathrm{~mm}$.

9) Faktor Kebocoran Dielektrik (Dielectric Dissipation Factor)

Faktor kebocoran dielektrik yang tinggi menunjukan adanya kontaminasi misalnya air, hasil oksidasi, logam alkali, koloid bermuatan dan sebagainya. Batas maksimal daripada faktor ini adalah 0.05.

10) Stabilitas atau Kemantapan Oksidasi (Oxydation Stability)

Pengujian stabilitas atau kemantapan oksidasi ini berguna untuk melihat apakah minyak tahan terhadap oksidasi. Batas nilai maksimal angka kenetralan pada pengujian ini maksimal $0.40 \mathrm{mgKOH} / \mathrm{g}$ dan nilai persentase kotoran maksimal $0.10 \%$.

11) Kandungan Air (Water Content)

Adanya kandungan air dalam minyak isolasi akan menurunkan tegangan tembus dan tahanan jenis minyak isolasi dan juga adanya air akan mempercepat kerusakan kertas pengisolasi (insulating paper). Batas maksimal nilai kandungan air pada minyak isolasi adalah 30 ppm.

12) Tahanan jenis (Resistivity)

Tahanan jenis atau resistivitas adalah kemampuan suatu bahan atau material dalam mencegah atau menghambat aliran arus listrik. Nilai resistivitas yang rendah menunjukkan adanya kontaminasi yang bersifat konduktif (conductive contaminants).

13) Tegangan Permukaan (Interfacial Tension)

Adanya kontaminasi dengan zat yang terlarut (soluble contamination) atau hasil hasil kerusakan minyak, umumnya menurunkan nilai tegangan permukaan. Penurunan tegangan permukaan juga menurunkan indikator yang peka bagi awal kerusakan minyak. Batas minimal nilai tegangan permukaan minyak isolasi adalah $43 \mathrm{mN} / \mathrm{m}$.

14) Kandungan Gas (Gas content)

a. Adanya gas terlarut dan gas bebas dalam minyak isolasi dapat digunakan untuk mengetahui kondisi transformator dalam operasi.

b. Adanya gas $\mathrm{H}_{2}, \quad \mathrm{CH}_{4}, \mathrm{C}_{2} \mathrm{H}_{6}, \mathrm{C}_{2} \mathrm{H}_{4}, \mathrm{C}_{2} \mathrm{H}_{2}$ menunjukkan terjadinya dekomposisi minyak isolasi pada kondisi operasi, sedangkan adanya $\mathrm{CO}_{2}$ dan $\mathrm{CO}$ menunjukkan adanya kerusakan pada bahan isolasi.

Secara jelas SPLN juga memberikan spesifikasi minyak isolasi baru yang ditunjukkan oleh Tabel 1. berikut [12]:

\begin{tabular}{|c|c|c|c|c|c|}
\hline No. & Sifat & Satuan & $\begin{array}{c}\text { Kelas } \\
1\end{array}$ & $\begin{array}{c}\text { Kelas } \\
2\end{array}$ & $\begin{array}{c}\text { Metode } \\
\text { Ujii }\end{array}$ \\
\hline 1 & Kejernihan & $\begin{array}{c}\text { Gardner } \\
\text { Scale }\end{array}$ & \multicolumn{2}{|c|}{3,5} & $\begin{array}{l}\text { IEC } \\
296\end{array}$ \\
\hline 2 & $\begin{array}{l}\text { Massa } \\
\text { Jenis } \\
\left(20^{\circ} \mathrm{C}\right)\end{array}$ & $\mathrm{g} / \mathrm{cm}^{3}$ & \multicolumn{2}{|c|}{$\leq 0,895$} & $\begin{array}{l}\text { IEC } \\
296\end{array}$ \\
\hline \multirow[t]{3}{*}{3} & $\begin{array}{l}\text { Viskositas } \\
20^{\circ} \mathrm{C}\end{array}$ & $\mathrm{cSt}$ & $\leq 40$ & $\leq 25$ & $\begin{array}{l}\text { IEC } \\
296\end{array}$ \\
\hline & $\begin{array}{l}\text { Kinematika } \\
:-15^{\circ} \mathrm{C}\end{array}$ & $\mathrm{cSt}$ & $\leq 800$ & - & $\begin{array}{l}\text { IEC } \\
296\end{array}$ \\
\hline & $-30^{\circ} \mathrm{C}$ & $\mathrm{cSt}$ & - & $\leq 800$ & $\begin{array}{l}\text { IEC } \\
296\end{array}$ \\
\hline 4 & Titik nyala & ${ }^{\circ} \mathrm{C}$ & $\geq 140$ & $\geq 130$ & $\begin{array}{c}\text { IEC } \\
296 \text { A }\end{array}$ \\
\hline 5 & Titik tuang & ${ }^{\circ} \mathrm{C}$ & $\leq-30$ & $\leq-40$ & $\begin{array}{l}\text { IEC } \\
296\end{array}$ \\
\hline 6 & $\begin{array}{l}\text { Angka } \\
\text { kenetralan }\end{array}$ & $\begin{array}{c}\mathrm{mg} \\
\mathrm{KOH} / \mathrm{g}\end{array}$ & \multicolumn{2}{|c|}{$<0,03$} & $\begin{array}{l}\text { IEC } \\
296\end{array}$ \\
\hline 7 & $\begin{array}{l}\text { Korosi } \\
\text { belerang }\end{array}$ & - & \multicolumn{2}{|c|}{ Tidak korosif } & $\begin{array}{l}\text { IEC } \\
296\end{array}$ \\
\hline \multirow[t]{3}{*}{8} & $\begin{array}{l}\text { Tegangan } \\
\text { tembus }\end{array}$ & $\begin{array}{c}\mathrm{kV} / 2,5 \\
\mathrm{~mm}\end{array}$ & & & \\
\hline & $\begin{array}{l}\text { a. } \\
\text { sebelum } \\
\text { diolah }\end{array}$ & - & \multicolumn{2}{|c|}{$\geq 30$} & \\
\hline & $\begin{array}{l}\text { b. sesudah } \\
\text { diolah }\end{array}$ & - & \multicolumn{2}{|c|}{$\geq 50$} & \\
\hline 9 & $\begin{array}{l}\text { Faktor } \\
\text { kebocoran } \\
\text { dielektrik }\end{array}$ & - & \multicolumn{2}{|c|}{$\leq 0,05$} & $\begin{array}{l}\text { IEC } \\
250\end{array}$ \\
\hline \multirow[t]{3}{*}{10} & $\begin{array}{l}\text { Ketahanan } \\
\text { oksidasi }\end{array}$ & & & & \multirow{3}{*}{$\begin{array}{c}\text { IEC } \\
474 \& \\
\text { IEC } 74\end{array}$} \\
\hline & $\begin{array}{l}\text { - angka } \\
\text { kenetralan }\end{array}$ & $\begin{array}{c}\mathrm{mg} \\
\mathrm{KOH} / \mathrm{g}\end{array}$ & \multicolumn{2}{|c|}{$\leq 0,40$} & \\
\hline & - kotoran & $\%$ & \multicolumn{2}{|c|}{$\leq 0,10$} & \\
\hline 11 & $\begin{array}{l}\text { Kandungan } \\
\text { air }\end{array}$ & ppm & \multicolumn{2}{|c|}{30} & $\begin{array}{l}\text { IEC } \\
814\end{array}$ \\
\hline 12 & $\begin{array}{l}\text { Tegangan } \\
\text { permukaan }\end{array}$ & $\mathrm{mN} / \mathrm{m}$ & \multicolumn{2}{|c|}{$\geq 43$} & $\begin{array}{l}\text { IEC } \\
296\end{array}$ \\
\hline
\end{tabular}




\section{METODE}

A. Pembuatan Minyak Metil Ester Bunga Matahari dari Reaksi Transesterifikasi

Minyak kedelai yang telah diperoleh akan melalui proses reaksi transesterifikasi untuk memperoleh metil ester. Proses transesterifikasi ini dilakukan dengan menambahkan campuran metanol dan kalium hidroksida $(\mathrm{KOH})$ ke dalam minyak kedelai yang sudah dipanaskan sebelumnya hingga suhu 55-60 0C. Kemudian minyak dan larutan diaduk menggunakan magnetic stirrer selama \pm 2 jam dengan kecepatan $500 \mathrm{rpm}$. Hasil yang diperolah kemudian dimasukkan kedalam corong pemisah dan didiamkan selama 24 jam. Setelah didiamkan selama 24 jam maka akan didapat 2 lapisan, lapisan atas adalah metil ester dan lapisan bawah adalah gliserol, setelah itu dipisahkan secara perlahan-lahan kedua lapisan tersebut melalui saluran pembuangan corong pemisah. Kemudian metil ester dicuci beberapa kali dengan menggunakan aquadest yang sudah dipanaskan (suhu $90{ }^{\circ} \mathrm{C}$ ) sampai $\mathrm{pH}$ bersifat netral. Selanjutnya metil ester dipanaskan menggunakan vacuum oven untuk menghilangkan sisa dari aquadest, metanol, dan katalis yang tercampur.

B. Pembuatan sampel uji

Sampel A merupakan minyak mineral murni, Sampel B merupakan minyak campuran $10 \%$ minyak metil ester biji bunga matahari dengan $90 \%$ minyak mineral. Sampel C adalah minyak campuran $20 \%$ minyak metil ester biji bunga matahari dengan $80 \%$ minyak mineral. Sampel D merupakan campuran antara $30 \%$ minyak metil ester biji bunga matahari dengan $70 \%$ minyak mineral. Sampel E adalah minyak metil ester biji bunga matahari murni. Diagram alir (flowchart) pembuatan sampel uji dapat dilihat pada Gambar 2.

\section{Pengujian Tegangan Tembus}

Metode pengukuran tegangan tembus peneltian ini berdasarkan standarisasi SPLN 49-1-1982 yang mengacu kepada IEC 60156-95, dimana pengukuran tegangan tembus menggunakan elektroda jenis bola-bola serta dengan jarak elektroda sebesar $2.5 \mathrm{~mm}$. Pengukuran tegangan tembus dilakukan sebanyak lima kali percobaan, di mana masingmasing percobaan dijeda selama beberapa menit, guna sampel melakukan self healing. Masing-masing sampel dilakukan pengukuran tegangan tembus dengan variasi suhu yaitu keadaan suhu normal $\left(28.7^{\circ} \mathrm{C}\right), 40{ }^{\circ} \mathrm{C}, 60^{\circ} \mathrm{C}$, dan 80 ${ }^{\circ} \mathrm{C}$.

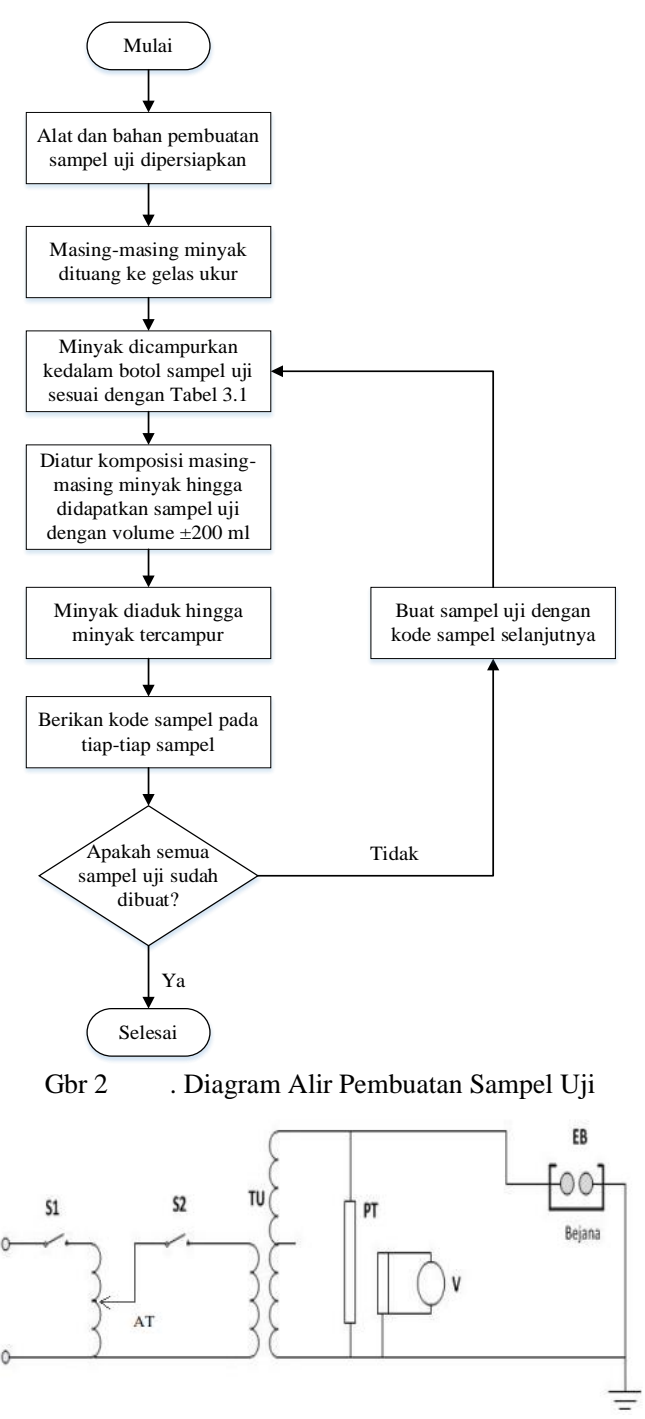

Gbr 3. Rangkaian Pengujian Tegangan Tembus

\section{HASIL DAN PEMBAHASAN}

\section{A. Hasil Pengujian Tegangan Tembus}

Pada Gambar 4. menunjukkan grafik hubungan tegangan tembus terhadap temperatur yang diperoleh dari nilai rata-rata pengukuran. Setiap sampel memiliki hasil pengukuran tegangan tembus cenderung meningkat ketika temperaturnya dinaikkan dari $28.7^{\circ} \mathrm{C}$ hingga $80{ }^{\circ} \mathrm{C}$.

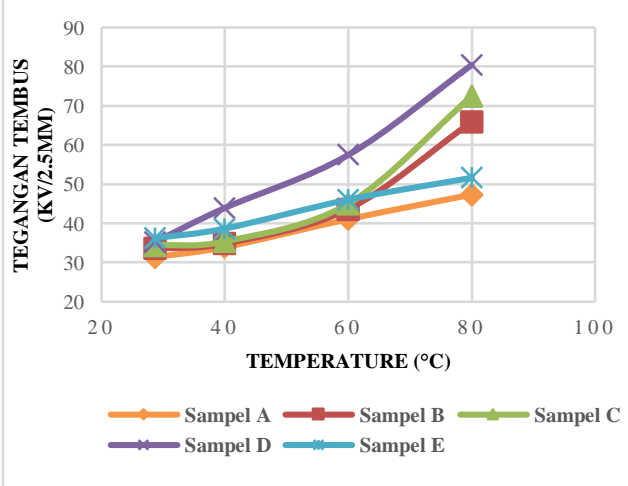

Gbr 4. Garifk Hasil Pengujian Tegangan Tembus untuk masingmasing Temperatur 


\section{B. Hasil Pengujian Tegangan Tembus}

Dari perhitungan nilai kekuatan dielektrik masing-masing sampel didapat juga grafik karakteristik yang menyatakan hubungan antara kekuatan dielektrik sampel minyak terhadap temperatur seperti pada Gbr 5.

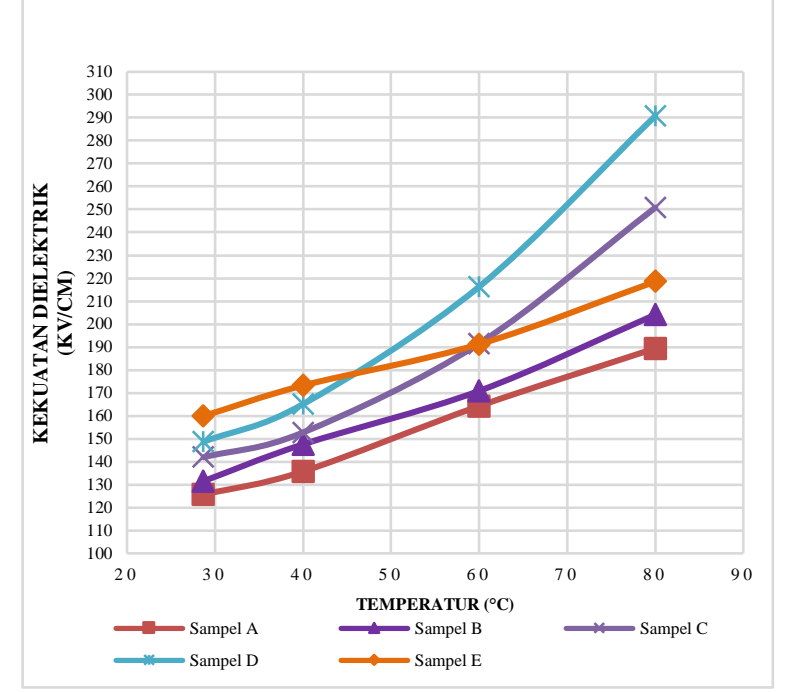

Gbr 5. Garifk Hasil Pengujian Tegangan Tembus untuk masingmasing Temperatur

Terlihat bahwa kekuatan dielektrik tiap-tiap sampel minyak cenderung meningkat ketika temperatur sampel minyak dinaikkan dari $28.7{ }^{\circ} \mathrm{C}-80{ }^{\circ} \mathrm{C}$. Hal ini terjadi pemuaian terhadap molekul-molekul pada sampel minyak sehingga jarak antar molekul semakin jauh seiring meningkatnya temperatur [16]. Peningkatan temperatur sampel minyak juga menyebabkan tingkat kontaminasi pada minyak semakin turun yang menyebabkan nilai kekuatan dielektrik minyak semakin tinggi [17]. Pada suhu normal $\left(28.7^{\circ} \mathrm{C}\right.$ ) dan suhu $40{ }^{\circ} \mathrm{C}$ sampel minyak dengan kekuatan dielektrik terbaik yaitu Sampel E dengan nilai rata-rata kekuatan dielektrik sebesar $159.89 \mathrm{kV} / \mathrm{cm}$. Saat temperatur meningkat dari $60{ }^{\circ} \mathrm{C}-80{ }^{\circ} \mathrm{C}$, kekuatan dielektrik terbesar dimiliki oleh Sampel D. Berdasarkan standar SPLN 49-11982, semua sampel uji sudah sesuai standar yaitu minimal $\geq 30 \mathrm{kV} / 2.5 \mathrm{~mm}$ atau dengan kekuatan dielektrik sebesar $\geq 120 \mathrm{kV} / \mathrm{cm}$.

\section{KESIMPULAN}

Seluruh sampel uji campuran minyak metil ester bunga matahari sudah memenuhi standar yaitu diatas $120 \mathrm{kV} / \mathrm{cm}$ dengan metode uji IEC 60156-95, Sampel D merupakan campuran antara $30 \%$ minyak metil ester biji bunga matahari dengan $70 \%$ minyak mineral memiliki nilai tegangan tembus $72.68 \mathrm{kV} / 2,5 \mathrm{~mm}$, dan kekuatan dielektrik sebesar 290.74 $\mathrm{kV} / \mathrm{cm}$. analisis kimia fisik seperti viskositas, titik nyala, dan kadar asam perlu dilakukan kedepannya untuk mengetahuo apakah campuran minyak metil ester bunga matahari dapat digunakan sebagai minyak isolasi baru.

\section{REFERENSI}

[1] T. Mayawati, STATISTIK PERTAMBANGAN MINYAK DAN GAS BUMI 2014 - 2019, Jakarta: Badan Pusat Statistik Indonesia, 2020.

[2] C. C. Claiborne, E. J. Walsh and T. V. Oomen, "An Agriculturally Based Biodegradable Dielectric Fluid," pp. 876-881, 1999.

[3] T. V. Oomen, C. C. Claiborne, E. J. Walsh and J. P. Baker, "A New Vegetable Oil Based Transformer Fluid: Development and Verification," Conference on Electrical Insulation and Dielectric Phenomena , pp. 308-312, 2000.

[4] A. S. Siva, C. Balaji, V. Akileshwaran and N. Hemanathan, "Experimental Analysis on the Combination of Jatropha Oil and Silk Cotton Oil for Transformer," International Conference on Science Technology Engineering and Mathematics (ICONSTEM), pp. 343-347, 2019.

[5] I. Fernández, A. Ortiz, F. Delgado, C. Renedo and S. Pérez, "Comparative Evaluation of Alternative Fluids for Power Transformers," Electric Power Systems Research, pp. 58-69, 2013.

[6] M. Dhofir, N. R. Dona, U. Wibawa and R. N. Hasanah, "Minyak Kepala Beraditif Minyak Zaitun sebagai Isolasi Peralatan Tegangan Tinggi," EECCIS, vol. 11, pp. 69-76, 2017.

[7] M. H. Hamid, M. T. Ishak, M. F. Md. Din, N. S. Suhaimi and N. I. Katim, "Dielectric Properties of Natural Ester Oils Used for Transformer Application Under Temperature Variation," pp. 54-57, 2016.

[8] R. A. Sitompul and Syahrawardi, "Analisis Kekuatan Dielektrik Minyak Kedelai (Soybean Oil) Dengan Variasi Suhu sebagai Alternatif Minyak Isolasi," Jurnal Singuda Ensikom, vol. 14, pp. 19-24, 2016.

[9] N. Srinivasan and S. Chandrasekar, "Investigations On Partial Discharge, Dielectric and Thermal Characteristics of Nano SiO2 Modified Sunflower Oil for Power Transformer Applications," Journal of Electrical Engineering and Technology, pp. 1337-1345, 2018.

[10] B. L. Tobing, Dasar-Dasar Teknik Pengujian Tegangan Tinggi, Jakarta: Penerbit Erlangga, 2012.

[11] M. S. Naidu and V. Kamaraju, High Voltage Engineering 2nd Edition, McGraw-Hill, 1996.

[12] SPLN 49 - 1, Specification For New Insulating Oils For Transformer and Switchgear, Perusahaan Umum Listrik Negara, 1982.

[13] Joelianingsih, A. H. Tambunan, T. H. Soeradijaya, Y. Sagara and K. Abdullah, "Prediksi Kualitas Biodiesel Berdasarkan Komposisi Asam Lemak Bahan Mentah (Minyak-lemak)," Jurnal Keteknikan Pertanian, vol. 22, 2008

[14] Y. Li, F. Qiu and D. Yang, "Transesterification of Soybean Oil and Analysis of Bioproduct," IChemE, pp. 135-140, 2012.

[15] T. Patzek, "A First Law Thermodynamic Analysis of Biodiesel Production From Soybean," Bulletine of Science Technology \& Society, 2008.

[16] A. M. Abd-Elhady, M. E. Ibrahim, T. A. Taha and M. Izzularab, "Effect of Temperature On AC Breakdown 
Voltage of Nanofilled Transformer Oil," IET Journals, vol. 12, no. 1, pp. 138-144, 2018.

[17] W. K. Wibowo, H. Nugroho, N. I. Pertiwi and A. Irawan, "Analisis Efek Viskositas Terhadap Tegangan Tembus Minyak Transformator," Jurnal Teknologia, vol. 1, no. 1, pp. 16-21, 2018.

[18] S. Arita, R. D. Ariani and S. Fatimah, "Pengaruh Waktu Esterifikasi Terhadap Proses Pembentukan Metil Ester (Biodiesel) Dari Minyak Biji Karet (Rubber Seed Oil)," Jurnal Teknik Kimia, vol. 16, no. 1, pp. 55-60, 2009.

\section{BIOGRAFI PENULIS}

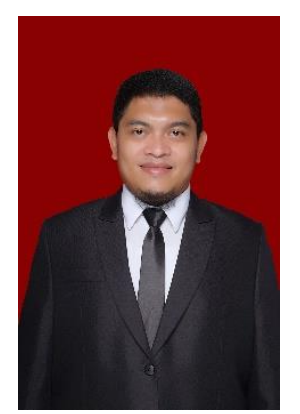

Ferry Rahmat Astianta Bukit, Lahir di Medan, 17 September 1989. Riwayat Pendidikan S1 Teknik Elektro, Fakultas Teknik Universitas Sumatera Utara dan S2 Teknik Elektro, Sekolah Tinggi Teknik Elektro dan Informatika (STEI) Institut Teknologi Bandung. Saat ini bekerja sebagai Dosen di Departemen Teknik Elektro Fakultas Teknik Universitas Sumatera Utara dengan focus keilmuan Konversi Energi, Material Teknik, dan Sistem Tenaga Listrik. 